\section{THE SUN'S PLACE IN NATURE.1}

\section{I.}

WHEN, in 1886 , it became my duty to give a course of lectures here, I thought it advisable to deal with the sun and stars, not with reference specially to solar physics, but in order to give a general idea of two important lines of work which were running then nearly parallel to each other, and promised soon to meet, with the greatest benefit to science. Only a very little was said in those lectures touching the relation of stars to nebulæ, and the various views which have been held time out of mind with regard to the special nature of both these classes of celestial bodies. Such questions, however, have always had the greatest interest for wankind, for those at all events among us who like to know something about the universe in which our lot is cast. No dividends, unfortunately or fortunately, depend upon the discussion or even the application of any branches of inquiry which are necessary in order to make progress along the lines of thought thus opened up; scant attention is paid to them by educational bodies, for they lead to no profession; but in suite of that, some of the noblest triumphs of the human mind have been made in that region where man finds himself face to face with the mysteries of the distant heavens.

To consider completely the Sun's Place in Nature, which is the subject I have chosen for this present course of lectures, the relation of these two apparently different classes of celestial bodies to which I have referred, must be gone into. Thanks to the advance of modern science, I shall be able byand-by to throw upon the screen pictures of clusters of stars, and of nebulæ, in which you will see those bodies very much better than you could do if to-night you were in one o the best equipped observatories in the world, for it so happens that the enormous progress which has recently been made in the application of photography to astronomical work enables us to get permanent records of parts of them which are so dim that they never have been and never will be directly revealed to the eye of mortals.

When we compare these two great groups of celestial bodies we find that, at all events in appearance, there is an enormous difference between them; that a nebula is certainly unlike a star, or even an ordinary star cluster. This is so obvious that even those who first observed those very few nebulæ which are visible to the naked eye (such a one, for instance, as that which is now beautifuily visible to us in the early night in the nebula of Orion, or the other in Andromeda, which we can see almost throughout the year), the greatest wonderment was caused by their strange appearance.

Let us go back 150 years. I have here a book ("Les Hypothèses Cosmogoniques"), recently written by a distinguished French astronomer, M. Wolf, which contains a reference to what the French philosopher Maupertuis said about them in the year 1745. "The first phenomenon is that of those brilliant patches in the sky which are named nebulæ, and have been considered as masses or groups of small stars; but our astronomers, with the aid of better telescopes, have only seen them as great oval areas, luminous and with a light brighter than the rest of the heavens. Huygens first discovered one in the constellation of Orion; Halley, in the Philosophical Transactions, pointed out six, the first in the Sword of Orion, the second in the constellation of Sagit tarius, thethird in the Centaur, the fourth before the right foot of Antinous, the fifth in Herculis, and the sixth in Andromeda. Five of these spots having been observed with a reflector of $8 \mathrm{ft}$, , only one of them, the fourth, could be taken for a group of stars; the others seem to be great shining areas, and do not differ among themselves, except that some are more round and others more oval in shape. It seems also that in the first the little stars which one discovers with the telescope are not capable of causing this brightness. Halley was much struck with these phenomena, which he believes capable of explaining a thing which seemed difficult to understand in the Book of Genesis, viz. that light was created before the sun. Durham regards them as holes through which one discovers an immense region of light, and finally the empyrean heaven itself. He professes to have been able to distinguish that the stars which are seen in some of them are very much less distant from us than the spots of light themselves."

1 Revised from shorthand notes of a course of lectures to working men at the Museum of Practical Geology during November and Decemter, r894:

"Discours sur les différentes figures des Astres," chap. vi. pp. 104- ¿4.
I need not follow the quotation any further, but you see that 150 years ago some of our keenest intellects were strug gling with the questions involved in mystery which had been started by the discovery of these nebulous bodies in space. That was in the year 1745 . Soon after this, in the year 1755 , Kant, who was a German, though he was by direct descent a Scotchman, brought out an hypothesis in which he altempted to show that there was the cloiest possible connection between stars and the clusters and nebulæ of which Maupertuis spoke. He held distinctly that the stars were produced by some action brought about in nebulæ; in other words, that the nebula represented a first staye out of which stars, representing a later stage, were proluced by certain processes of evolution.

From 1755 we pass to 1796 , at which date we find a great Frenchman (Laplace) practically rediscovering and reasserting the same thing. It is believed that he hnew nothing of Kant's prior work, an" therefore we have the advantage of dealing with the results of the thoughts of two great minds. Laplace came to the same conclusion as Kan , so far as it went, but be went further than Kant did, bec iuse he held that the nebula really represent enormous masses of elastic gas at high temperature, and that therefore the stars, which he conceived, as Kant had conceived, to be produced hy evolutionary processes. from these nebulæ, were really produced from incandescent masses of gas.

Now, seeing that our sun is a star, it is perfectly clear from this that both Kant and Laplace agreed that the sun, represent ing a star, had originally been produced from a nebula. That is my first point.

About the time of Laplace, i.e. abou, 1796, Sir William Herschel was making England famous by the discoveries rendered possible by that w.nnderful telescope which he had erected at Slough. There, for the first time, the possible similarities and the possible differences of these two great groups of celestial bodies were subjected to the most minute and lab. orious scrutiny. Well, he came a'ssolusely to the same conclasion as his predecessors had done, and for Sir William Herschel there was no doubt whatever that from the most irregular nebula $t$, the densest star there was a gradual process of change; that there was no radical difference, but that the star repreiented simply the result of certain evolutionary changes. This view thus strengthened held the field for some years; then a larger telescope was made by Lord Rosse, a 6 foot mirror was now availahle instead of the 4-loot one which had been erected by Herschel at Slough. Lord Rosse-you will find the whole story admiralily told in Prof. Nichol's book, "The Architecture of the Heavens"-came to the conclusion that when he observed a so-called nebula on the finest possible nights, when the air was stillest; and the magnifying power which he could use was greater than usual, he could see what he called the possibility of a resolvabulity in it. That is to say, nebula might after all really be star clusters, only immensely rem ste, so that the light of all the stars was, as it were, so welded together as to give that appearance of a candle seen through horn, which Maupertuis and his predecessors had observed.

Next we come to the year 1862 , and we find a new instrument brought to bear, which at once drove into thin air all the statements which had been made on what had turned out to be a line of inquiry which was incapable of giving a final verdict. It so happened that in that year there was a very powerful combination formed by a distinguished chemist and philo. sopher, Dr. Williarn Allen Miller, the Treasurer of the Royal Society, who had already done most admirable spectroscopic work, and a neighbour of his, Mr. Huggins, who had mounted a powerful telescope in $185^{6}$ The spectroscope, which was then practically a new instru nent, was applied to the telescope.

I need not say much about the spectroscope, as I have alre ady had an opportunity of describing it to some of you, but I may in a few words show exactly the function of this new instrument of enormous power, which has in a very few years perfectly changed the aspect of astronomic science. If we pass a ray of white light through a piece of glass called a prism, we find that after the light has so passed through, it is changed iato a beautiful band, showing all the colours of the rainbow. This prism then is the fundamental part of the instrument which is called the spectroscope, and the most complicated spectroscope which we can imauine simply utilises the part which this piece of triangular glass plays in breaking a beam of light of any colour 
into its constituent parts from the red to the violet; between these colours we get that string of orange yellow, green, and blue which you are familiar with in the rainbow. For sixpence any of you may make for yourselves an instrument which will serve many of the purposes of demonstrating some of the more beautiful fields of knowledge which have been opened up

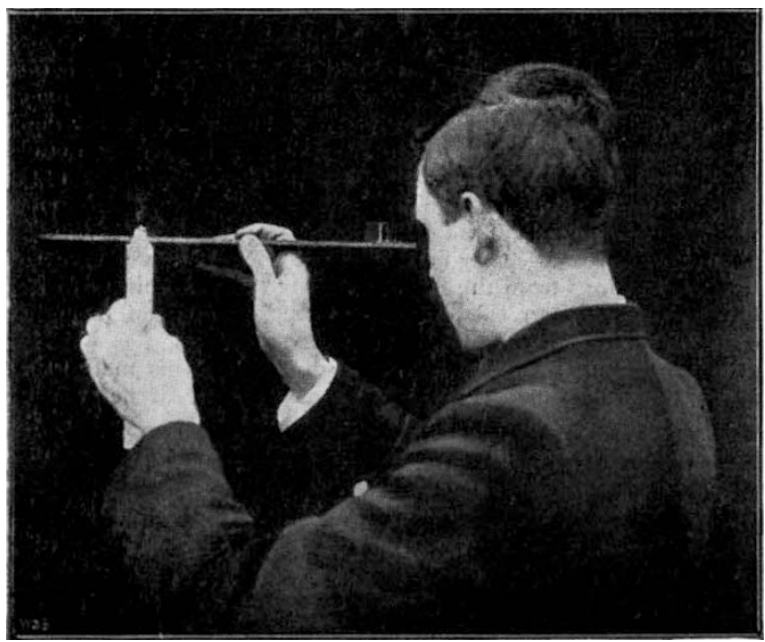

FIG. 1,-A simple form of spectroscope.

to us by its use. From an optician you can get a tiny prism for sixpence; glue it at one end of a piece of wood about $12 \times 1 \times \frac{1}{2}$ inch, so that you can see through it a coloured image of a needle stuck in at the other end of the piece of wood (Fig. I). This you must $\mathrm{d}$, by looking sideways throughit. Allow your needle to be illuminated by a candle or a gas

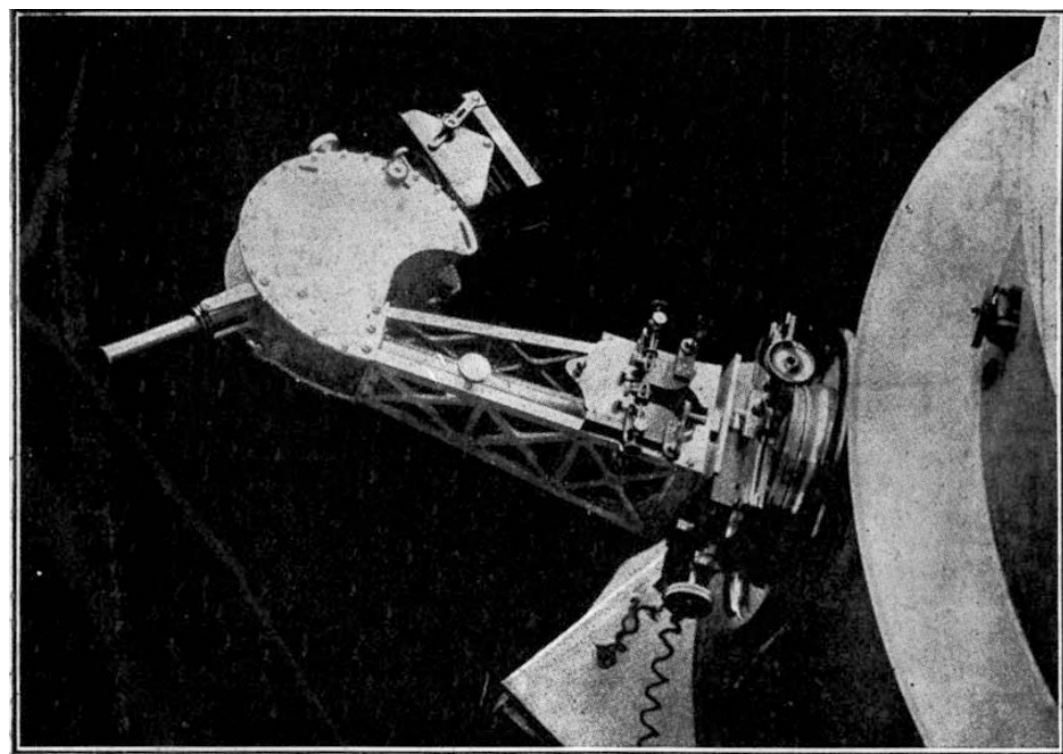

FIG. 2.-Star spectroscope, arranged for photographing, attached to eye-end of reflecting telescope.

flume, taking care that the direct light from the candle does not fall upon the face of the prism; you will then get a complete band of colour from red to blue. If you go into the sunlight-taking care again to protect the prism itself from the entrance of any foreign light-and allow the sunbeam to illuminate your needle, you get a spectrum of a different kind, full of black lines.
By such experiments as that, certain spectroscopic axioms have been formulated : three of them are very important.

First, when solid or liquid or densely gaseous bodies are incandescent, they give out continuons spectra.

Second, when a solid or liquid body reduced to a state of gas, or any gas itself, is giving light, the spectrum consists of bright lines, and these lines are different for different substances.

Third, when light from a solid or liquid body passes through gas at a lower temperature, the gas absorbs those particular rays of light of which its own spectrum consists.

We will next suppose, then a spectroscope placed at the eyeend of a telescope (Fig. 2). The question put to the combined instruments is : What is starlight like? It was found that the stars give a spectrum very much like the spectrum of the sun, in most cases at all events, and that this spectrum could be defined in the light of the third axiom, that certain of the light was ab. sorbed, there were dark lines in the spectrum(Fig. 3); and thus we knew that light had been absorbed by an atmosphere surround. ing something which was very much hotter than itself, and in that way the science of solar and stellar physics was founded.

Suppose another question put to this instrument: What is the light of the nebulæ like?

I have already told you that Laplace held that in these bodies we were dealing with gas at a high temperature. From the time of Tycho Brahe downuards, people had an idea that the netulæ were "fiery." What should we expect to get in our instrument? The second axiom tells us that, if we are dealing with matter in a state of gas, or anything vapourous at very high temperature, we shall get bright lines only. The question as to the nebulæ was put in 1864, and, curiously enough, when the observation was made, Dr. Huggins remarked : "I suspected some derangement of the instrument had taken place, for no spectrum was seen, but only a line." "Only a line" was exactly what I suppose Laplace would have given all he possessed to see, if spectrum analysis had been invented in his day. That line settled the question. There was certainly a tremendous spectro. scopic difference between stars and nebulæ, and this difference has been emphasised by subsequent researches. (See Fig. 3.) It is evident, therefore, that Lord Rosse's sus. picion that the rebulæ might, after all, be found to be resolvable into star clusters when greater optical power was used, was proved to be erroneous.

Now we come to the second point. I indicated in the previous course of lectures that th re were differences among the stars, depending possibly upon chemical constitution, or temperalure, or even upon their ages, and that the stars had been classified by several very diligent inquirers. Also, that in all the classifications that had been attempted, it was universally taken for granted, for some reason or other-possibly in view of the idea of Laplace--that all the stars in the heavens began in the condition of highest temperature, and that all that the stars did after that was to spend their millions and billions of years of life in getting colder; so that, if we could at the present moment find out which was the very hottest star in the heavens, we might be perfectly certain that every star in its beginning resembled exactly in spectrum, and therefore in physical constitution, that particular star which we sup pose to be the hottest. It so happened that in that very course of lectures I pointed ou!, for the first time, I think, in reference to the separation of stars into classes, that such an idea as that would never do; for if we form any conception of nebulæ changing into stars, we begin by knowing that the stars are very much denser than we begin by knowing that the stars are very much denser than close to us-and that as the stars are denser than the nebula, they must be hotter than the nebulæ, instead of being colder. 
This depended absolutely upon the application of thermodynamics, and had been pointed out by Helmholtz in the year 1845. Sir William Thomson, now Lord Kelvin, also pointed out quite distinctly that the hypothesis of fiery nebulous matter -by that meaning nebulous matter hotter than the starswas invented before the discovery of thermo-dynamics; otherwise, he said, the nebulæ would certainly never have been conceived to have been fiery, i.e. something hotter than the zverage star.

I then went on to show that Lord Kelvin told us how he could imagine a condition of nebulæ which might ultimately condense into stars without violating the laws of thermodynamics, which were completely traversed by Laplace's view ; and he referred to a suggestion that had been made by Prof. Tait, who supposed that the Iuminosity of nebulæ, and even the spectroscopic appearances which have been observed, might be explained by supposing that we were dealing with gaseous exhalations proceeding from the collisions of meteoric stones; and he also pointed out that possibly that would not only explain the luminosity of nebulæ, but the luminosity of comets as well. By the kindness of the Director of this Museum, I have some specimens of these meteoric stones on the table. I would re- might be explained by the fact that, in consequence of the collisions between these bodies occurring under different conditions and at different velocities, there would be very considerable differences in the temperatures produced in the two cases. Similar conditions might hold for stars in different degrees of condensation. It was also suggested that this new idea might explain the phenomena of variable and new stars, which have always been accounted to be the most extraordinary and mysterious in the whole domain of astronomy; and, finally, I said the subject was well worthy of study, because it seemed as if many phenomena on the nearest star to us, our own sun, might be really phenomena produced by the fall of meteoric bodies upon that surface which we see, and which we call the photosphere. It is now many years ago since Balfour Stewart and others threw out the idea that the phenomena connected with the formation of sun-spots were really produced by the fall of bodies upon that surface. Other philosophers have preferred the idea that we have to do with eruptions from the interior of the sun; nothing can be more divergent than the opinions which have been brought forward as explarations of these appearances.

But you at once see that, if we assume that this meteortic action may take place in the solar atmosphere, it need not

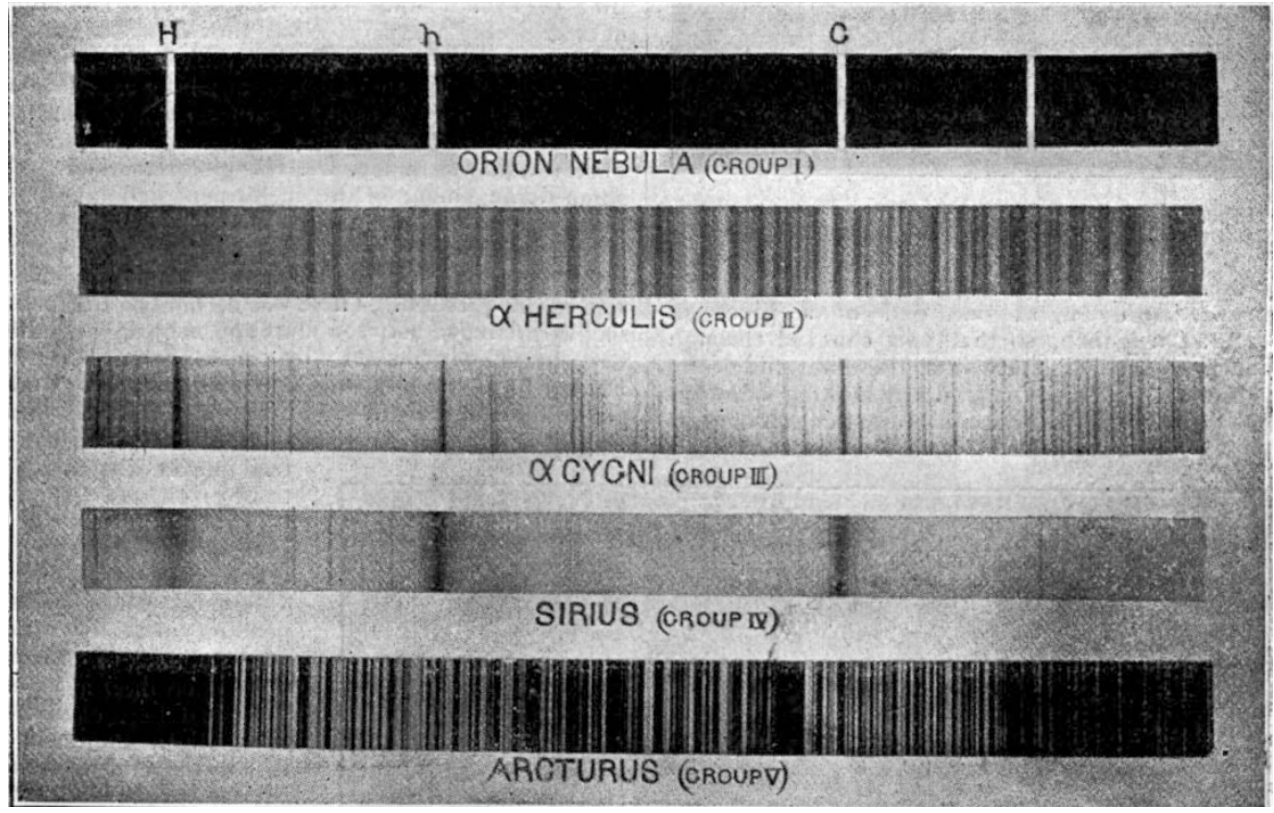

FIG. 3.-The photographed spectrum of a nebula, contiasted with the spectra of stars.

mind you that the few specimens which I have here have been selected from the magnificent collection upstairs; if you have a few minutes to spare after this lecture, you cannot do better than go and have a look at them, and you will see how very various both to the eye and in chemical and physical constitution they are. Let me also recommend you to get a little pamphlet (price $2 d$.) containing a description of the meteorile collection in the Natural History Museum, which is one of the finest in the world.

We thus arrived at the idea that these wonderful nebula may be explained, apart from any fiery gas ; that we have simply to look to a meteoritic origin to explain both the appearances and the spectrum.

After that point had been made, I went on to make another. I had already referred to the classification of stars, and $I$ remarked that if one looked at the different groups of spectra, it seemed as if a classification of them, based on these ideas, did fit the facts better, the existing ones depending on the unphilosophic one of Laplace. It is possible, I said, that the great differences which had been observed in the spectra of comets and of nebulæ, although the origin of the light of both was ascribed to the clashing together of stones in different parts of space,

NO. I320. VOL. 5 I ] necessarily be a meteoritic action coming from without. Taking our own case, we live in a damp climate, and sometimes the air is dampest when there are no clouds. Clouds are condensativus of the moisture in the air, and we know that it is not really a question of clouds only; we may have snow, rain, or hail, and all these represent different condensations of the damp-or, as we call it, the aqueous-vapour which is ever present in our air. Apply that to the sun. What is the air of the sun composed of? Well, certainly one important constituent of it is the incan. descent vapour of iron; we are no longer dealing with a low temperature and the vapour of water, but with an atmosphere in the hotter parts of which iron is not solid or liquid, but in which the temperature is high enough to keep it in a state of gas, probably thousands of degrees higher than is arrived at in the Bessemer process.

We will assume, then, that that temperature and that condition of at mosphere prevails for 20,000 (it is probably nearer $50,000)$ miles above the photosphere of the sun. As we get lurther from the sun, the aimosphere is of course getting cooler, and at a certain distance above the photosphere the temperature will be so reduced that the iron vapour might play the part of our aqueous vapour; then it condenses and turns into iron snow 
and iron hail and irom rain, and so on, falling upon the photosphere as the rain falls on the earth. There is thus a possibility in the sun of home-made meteoritic action.

So far as my last course of lectures was concerned, I there ended that part of the subject. But so many points bad been raised in trying to give a connected view of these two very slowly converging lines of research to which I referred, that, after the lectures were over, I determined to discuss the various points which had been raised. I determined to take up Prof. Tait's suggestion, and see how all the spectrosenpic observations which had been made up to the time of my lectures in 1886 , bore out that suggestion which had been made in 1871 , before there was very much spectroscopic evidence to go upon. The result was that my assistants and myself spent something like three years in gathering together, we believe, every available observation; at all events, if not every available observation, there were between thirty and forty thousand of them, and we found that a very considerable number. I not only determined to collect them, but also to discuss them, and make any experiments or observations which might be suggested by the discussion. The result of this was that, as a fruit of that course of lectures, several papers, some of them very long-it is not for me to say anything as to their value-were sent in to the Royal Society, and eventually brought together in a book.

Now, what I found was that when we discussed the meteoritic view in the light of all the observations we could get together, and in relation to stars as well as nebulæ and comets, it seemed to explain many things, and threw a perfectly new light upon the visible universe; there were, moreover, several points raised of intense novelty and freshness, each of which could be discussed separately, cast aside if it were false, and held on to if it were true. I give a table of some of these new points of view.

New points of view in the Meteoritic Hypothesis.

(I) There is the closest possible connection between nebula and stars.

(2) The first stage in the development of cosmical bodies is not a mass of hot gas, but a swarm of cold meteorites;

(3) Many bodies in space which look like stars are really centres of nebulæ; that is, of meteoritic swarms.

(4) Stars with bright-line spectra must be associated with nebulæ.

(5) Some of the heavenly bodies are increasing their temperatures; others are decreasing their temperatures.

(6) Double swarms, in any stages of condensation, may give rise to the phenomena of variability.

(7) New stars are produced by the clash of meteor swarms. They are closely related to nebulæe and bright-line stars.

(8) Cosmical space is a meteoritic plenum.

(9) A new classification of the heavenly bodies, based on the varying states of condensation of the meteoritic swarms.

(10) The sun is one of those stars the temperature of which is rapidly decreasing.

(II) Many of the changing phenomena of the sun are due to the fall of meteoritic matter upon the photosphere.

We ultimately arrived at the conclusion that the sun is one of the stars, the temperature of which is gradually decreasing, and that many of the phenomena of the sun are due to the fall of meteoritic matter on the photosphere.

The doing of a large piece of work like that-and I say it is large because I am glad to have the opportunity here of expressing my gratitude to my asistants, who stood by me for three years-brings one out pretty well into the open, and renders one liable to a brisk fire of criticisms, some very valuable, some quite unworthy of the critics.

You will see that the work was undertaken with a view of determining the sun's place among the stars.

(To be continued.)

J. NORMAN LOCKYer.

\section{THE INSTITUTION OF MECHANICAL} ENGINEERS.

THE annual general meeting of the Institution of Mechanical Engineers was held on Thursday and Friday evenings, the 3 Ist ult. and the Ist inst. Prof. A. B. W. Kennedy, F.R.S., occupied the chair. There were two papers set down for reading and discussion :

"The Determination of the Dryness of Steam." By Prof. W. Cawthorne Unwin, F.R.S.

No. 1320 , VOI, $5 !]$
"Comparison between Governing by Throttling and by Variable Expansion." By Captain H. Riall Sankey.

Prof. Unwin, in his interesting paper, gave descriptions of tho best known methods of determining the mean of moisture in steam up to now introduced. Most of the apparatus described was exhibited on the table of the theatre, whilst diagrams illustra. tive of them were hung on the wall. The author pointed out that the earliest attempts to determine the amount of moisture in steam, of which records have been found, were made during some boiler trials carried out by a committee of the Sociét Industrielle of Mulhouse in 1859. - This committee tried three different methods - a method of separation, a condensing method suggested by Hirn, and a chemical method. In these early trials the condensing method only, in which the total heat of a sample of the steam was measured, appeared to give satisfactory results. But although the committee did not place full reliance on any of their methods, these have all been used by various experimenters down to the present time.

The origin of water entrained in steam, Prof. Unwin said, was to be attributed to three causes :

(I) Water projected into the boiler's steam space during ebullition. The extent to which wetness occurs depends on the activity of the ebullition, the area of the water surface, the volume of the steam space, the position of the steam valve, the density of the steam, and, probably more than anything else, on the quality of the water and its liability to produce foam. The author referred to the experiments of $\mathrm{Mr}$. Thorny croft, who constructed a boiler with glass ends, through which the process of boiling could be seen. The result of observations on this boiler showed ${ }^{1}$ that waters which cause priming produce foam on boiling. Water which is very bad produces bubbles so durable as to remain a considerable time without breaking; and by them the steam space of a boiler may be entirely filled. So soon as this takes place, instead of simply steam leaving the boiler, the discharge consists of foam, which becomes broken up in its rapid passage through the steam-pipe. With pure water, steam retains no film of liquid long enough to be seen.

(2) Water may be produced in steam from the expansions to which it is subjected. Fluctuations of pressure arise from the intermittent demand for steam, and from the steam passing from places of higher to places of lower pressure. Prof. Unwin considered it difficult to believe that any great amount of wetness arises in this way in ordinary cases.

(3) The steam in the boiler, and the steam-pipes, loses heat by radiation. Probably in some cases considerable wetness is produced in this way. The wetness of the steam, so far as it is due to this cause, will increase as the demand for steam diminishes.

The author next went on to deal with the various methods of determining the wetness of steam, referring first to the weighing method, by which a known volume is weighed, when any excess of weight above that of a corresponding volume of dry saturated steam must be due to the water present. This method is obviously one of excessive difficulty.

The superheating method was next referred to in the paper, the experiments of Barrus and Carpenter being quoted. The Carpenter calorimeter consists of a vessel about 12 inches high by 5 inches diameter, consisting of an inner chamber and a jacket. The steam from the steam-pipe passes first to the inner chamber, where the moisture is separated, and then into the outer chamber. The separating chamber is therefore perfectly protected from radiation. As the water accumulates in the inner chamber, its level is shown by a gauge glass, and the amount in hundredths of a pound can be read off on a scale. A very small orifice at the bottom of the outer chamber regulates the amount of steam discharged. The escaping steam passes through a flexible tube to a simple form of condenser. The increase of weight in any given time in the condenser is noted, and the amount accumulated in the same time in the separator.

The condensing method was next described. This is founded on the condensation of a known weight of steam and the determination of its total heat by the rise of temperature in the condensing water. By comparing the total heat per pound of a sample of steam with that of a pound of dry saturated steam according to Regnault's tables, the amount of moisture in the steam can be determined. This method was first suggested by Hirn, and the apparatus which he designed is perhaps the most

1 "Circulation in the Thornycroft Water-Tube Boiler." Transactions of the Institution of Naval Architects, $\mathbf{8} 94$. 